\title{
Vasopressor-Sparing Action of Methylene Blue in Severe Sepsis and Shock: A Narrative Review
}

\author{
Filomena Puntillo - Mariateresa Giglio - Alberto Pasqualucci • \\ Nicola Brienza · Antonella Paladini · Giustino Varrassi (D)
}

Received: May 31, 2020 / Published online: July 23, 2020

(c) The Author(s) 2020

\section{ABSTRACT}

Shock is a serious acute circulatory failure leading to inadequate oxygen delivery to the

Digital Features To view digital features for this article go to https://doi.org/10.6084/m9.figshare.12613106.

\section{F. Puntillo}

Department of Interdisciplinary Medicine,

University of Bari “Aldo Moro", 70124 Bari, Italy

M. Giglio

Anesthesia, Intensive Care and Pain Unit,

Policlinico Hospital, 70124 Bari, Italy

\section{A. Pasqualucci}

Department of Surgical and Biomedical Science,

University of Perugia, 06100 Perugia, Italy

\section{A. Pasqualucci}

Rashid Hospital, Trauma and Emergency Center,

Dubai Health Authority, Dubai, UAE

N. Brienza

Department of Emergency and Organ

Transplantation, University of Bari "Aldo Moro", 70124 Bari, Italy

A. Paladini

Department of MESVA, University of L'Aquila,

67100 L'Aquila, Italy

G. Varrassi $(\bowtie)$

Paolo Procacci Foundation, Via Tacito 7, 00193

Rome, Italy

e-mail: giuvarr@gmail.com

G. Varrassi

World Institute of Pain, Winston-Salem, NC, USA cells. Its treatment is mainly based on circulating fluid optimization, and vasopressors to provide an adequate mean arterial pressure and microcirculatory flow. Norepinephrine is the drug of choice, but high dosages may be responsible for several side effects, including increased myocardial oxygen consumption, dysrhythmias, and peripheral and organ ischemia. Moreover, some patients are "non-responders" to first-line norepinephrine treatment. Hence, other drugs have been proposed to reach and maintain the hemodynamic target. In general, they are described as catecholaminesparing agents. Among others, the most used are vasopressin, corticosteroids, and angiotensin II. Methylene blue (MB) represents a further option, even though its use is still a topic of controversy. This review article tries to summarize what is known and unknown about the actions of $\mathrm{MB}$ in patients in shock. It reduces excessive production of nitric oxide via blockade of guanylate cyclase in shock states. At present, it appears the MB provides positive results in septic shock, if administered early. Further randomized controlled trials are warranted regarding its use to provide more precise indications to physicians involved in the treatment of such patients.

Keywords: Catecholamine; Catecholaminesparing agents; Methylene blue; Norepinephrine; Septic shock; Shock 
Key Summary Points

Shock is an acute circulatory failure leading to inadequate oxygen delivery to the body cells.

Its treatment is based on fluid optimization and vasopressor drugs. The drug of choice is norepinephrine.

In some cases, norepinephrine is not efficacious, and other vasoactive drugs like corticosteroids, vasopressin, and angiotensin II should be administered. Some authors also suggest the use of methylene blue.

Methylene blue has demonstrated efficacy if used very early, but the existing data are still too few.

This review article on the knowns and unknowns of methylene blue has tried to make clear whether the published data may be enough to draw conclusions useful to physicians.

\section{INTRODUCTION}

Shock is defined as an acute syndrome of circulatory failure leading to inadequate oxygen delivery to the cells [1]. A number of different pathophysiological mechanisms may cause shock, including cardiogenic factors, obstruction, distributive factors (anaphylaxis or sepsis), and hypovolemia. In intensive care patients, the most common type of shock is septic (62\%), followed by cardiogenic (16\%) and hypovolemic shock (16\%). Other types of obstructive and vasodilatory shock are relatively less frequent [1].

Treatment of distributive shock, the most frequent, is largely dependent on managing hypotension, ensuring adequate systemic and microcirculatory flow, and tissue oxygenation [2]. To improve arterial pressure, and therefore organ perfusion, intravenous vasopressors are often employed. Among others, norepinephrine is recommended as first choice to obtain mean arterial pressure (MAP) at greater than 60-$65 \mathrm{mmHg}$ [2]. This hemodynamic goal may require large doses of the drug. At high dosages, it may be responsible for added risk for adverse events such as dysrhythmias, peripheral ischemia, and increased myocardial oxygen consumption [3]. Other potential side effects include hypercoagulability, immunomodulation, and gastrointestinal peristalsis alterations, and extravasation [3]. Moreover, several patients are identified as "non-responders" to first-line norepinephrine treatment [2].

Because of the risks associated with catecholamine vasopressors, interest has grown in using catecholamine-sparing agents in order to achieve hemodynamic target with lower catecholamine doses. Although definitions for catecholamine-sparing agents vary, it is agreed that those medicines should reduce the norepinephrine dose by $50 \%$ or more for $4 \mathrm{~h}$ without any reduction from the patient's baseline MAP [4]. Well-known adjuvant agents used for catecholamine-sparing effects in shock include vasopressin, corticosteroids, whose effect on microcirculation has been demonstrated for about half century [5], and angiotensin II [4].

Methylene blue (MB) represents an additional option useful to provide a catecholamine-sparing effect, but its use is controversial. This review aims to summarize current evidence for $\mathrm{MB}$ as adjuvant therapy in critically ill patients with distributive shock. This article is based on previously conducted studies and does not contain any studies with human participants or animals performed by any of the authors.

\section{SHOCK: PATHOPHYSIOLOGY AND TREATMENT}

\section{Pathophysiology}

The definition of shock has evolved over centuries. In the eighteenth century, "shock" indicated a sudden deterioration of a patient's condition after a major trauma. While the term "shock" has taken on many meanings, the 
Table 1 Types of circulatory shock and their clinical features

\begin{tabular}{lllllll}
\hline Type of shock & MAP & CO & DO $_{2}$ & CVP & SVR & Clinical examples \\
\hline Hypovolemic & $\downarrow \rightarrow$ & $\downarrow$ & $\downarrow$ & $\downarrow$ & $\uparrow$ & Hemorrhage burns \\
Distributive & $\downarrow$ & $\uparrow$ & $\uparrow$ & $\downarrow$ & $\downarrow$ & SIRS/Sepsis anaphylaxis \\
Obstructive & $\downarrow$ & $\downarrow$ & $\downarrow$ & $\uparrow$ & $\uparrow \rightarrow$ & Pulmonary embolism tension PNX \\
Cardiogenic & $\downarrow \rightarrow$ & $\downarrow$ & $\downarrow$ & $\uparrow$ & $\uparrow$ & Myocardial infarction arrhythmia \\
\hline
\end{tabular}

$M A P$ mean arterial pressure, $C O$ cardiac output, $C V P$ central venous pressure, $S V R$ systemic vascular resistance, $\mathrm{DO}_{2}$ delivery of oxygen, SIRS systemic inflammatory response syndrome, $P N X$ pneumothorax, $\uparrow$ increased, $\downarrow$ decreased, $\rightarrow$ no change

current emphasis is on imbalance of tissue perfusion in relation to cellular oxygen demand. Whatever the cause might be, hemodynamic shock is characterized by a decrease in tissue perfusion associated with cellular and metabolic abnormalities. Therefore, the goal of shock resuscitation is to improve tissue perfusion by restoring perfusion pressure of vital organs, ensuring an adequate oxygen delivery $\left(\mathrm{DO}_{2}\right)$, and, when possible, improving microvascular alterations [6]. Hypovolemic shock is a condition of inadequate organ perfusion caused by loss of intravascular volume, resulting in decreased preload, stroke volume (SV), and cardiac output (CO) with a compensatory increase in systemic vascular resistance (SVR) in order to maintain perfusion. Distributive shock is characterized by a decrease of SVR and by an abnormal distribution of microvascular blood flow in the presence of normal or increased CO (Table 1). In septic shock, the response to pathogen-associated molecular patterns (PAMPS) and damage-associated molecular patterns (DAMPS) generates a combination of vasodilatation and increased capillary permeability. Capillary leak, coupled with greater vessel capacitance mediated by vasoplegia, may result in absolute or more commonly relative hypovolemia [7].

\section{Treatment}

Shock has been traditionally treated with fluids as a first step in order to increase preload and therefore SV and CO. However, because either too much or too little fluid can have a negative impact on patient outcomes, fluid administration must be carefully tailored to each patient. The "salvage, optimization, stabilization, deescalation" (SOSD) mnemonic rule has been proposed as a general guide to fluid resuscitation [8]. It suggests that in the initial salvage phase fluid should be administered generously, but once hemodynamic monitoring is available, fluid administration should be optimized by determining the patient's real fluid requirement. Dynamic tests of fluid responsiveness such as pulse pressure or stroke volume variation together with fluid challenge technique are the most frequently used to assess ongoing fluid requirements [9]. Once a patient has been stabilized, efforts should start to eliminate excess of fluids.

However, fluid administration alone is often insufficient to increase perfusion pressure. Vasopressors correct the underlying deficit in SVR, thus restoring MAP, perfusion pressure, and ideally tissue perfusion pressure. Autoregulatory threshold should be maintained to ensure perfusion to vital organs. The optimal MAP target probably lies between 65 and $75 \mathrm{mmHg}$ in most patient with sepsis [10]. Therefore, in this kind of shock, it seems reasonable to administer vasopressors in order to obtain the optimal blood pressure target (i.e., $\mathrm{MAP}>65 \mathrm{mmHg}$ ).

Norepinephrine, a potent $\alpha$ agonist and less potent $\beta$ agonist, is the vasopressor of choice in septic shock [11]. It increases smooth muscle intracellular calcium concentration and mediates vasoconstriction with some positive inotropic activity, increasing ventricular contractility. However, several patients are 
identified as "non-responders" to first-line norepinephrine treatment, i.e., when a pre-defined maximum dose was reached or when further increase of the first vasopressor was supposedly ineffective [2]. In norepinephrinerefractory patients, vasopressin or epinephrine may be added. Epinephrine has more $\beta_{1}$ agonism than norepinephrine, but its use is burdened by increased risk of splanchnic vasoconstriction, tachyarrhythmias, and hyperlactatemia. Vasopressors may in turn magnify sepsis-induced myocardial dysfunction, so inotropic agents (e.g., dobutamine) are commonly added to increase cardiac output. However, in recent years several concerns are arising regarding their use, since all these agents may cause direct organ damage and have multiple harmful biological effects on the immune system and metabolic and coagulation pathways (i.e., hyperglycemia; cardiac, cerebral, splanchnic, renal, and digital ischemia; hyperlactatemia) that can negatively affect patients' outcomes [6]. Moreover, all these pharmacological approaches act on macrocirculation variables, such as MAP, systemic vascular resistance index (SVRI), and CO, but an increased $\mathrm{CO}$ does not always meet the perfusion requirements of organs.

This condition (the so-called loss of hemodynamic coherence) [12] is most frequently found in the early phase of sepsis when a lack of microcirculatory recruitment is observed despite successful macrocirculatory resuscitation. The microcirculation can be considered as a vital organ whose function ensures the adequate $\mathrm{DO}_{2}$ to the various tissue cells [13]. It is a complex network of resistance and exchange vessels, where perfusion is dependent on numerous factors. The entire organ comprises endothelial cells, a layer of glycocalyx covering the endothelial cells and smooth cells. Vascular smooth muscle cells (VSMC) in the tunica media regulate vascular tone, depending on intracellular calcium $\left(\mathrm{Ca}^{2+}\right)$ concentration. Relaxation of the VSMC is driven by a decrease in cytosolic $\mathrm{Ca}^{2+}$, due to uptake of $\mathrm{Ca}^{2+}$ by the sarcoplasmic reticulum and expulsion of potassium $\left(\mathrm{K}^{+}\right)$or $\mathrm{Ca}^{2+}$ (via $\mathrm{K}^{+}$channels and $\mathrm{Ca}^{2+}$ ATPase pumps) into the extracellular space, resulting in cellular hyperpolarization and vasodilation. The endothelium regulates blood flow in response to local stimuli, resulting in upstream signaling to VSMC to dilate. The glycocalyx layer forms an important barrier and transduction system that can be disrupted under conditions of inflammation and cardiovascular disease. A large number of cellular components complete the picture: platelets, coagulation factors, cytokines, and chemokines. In sepsis, all the components of the microcirculation listed above are affected, causing a severe dysfunction in its regulatory function and resulting in a regional mismatch of oxygen supply and demand [13].

\section{NITRIC OXIDE}

In various conditions of distributive shock such as sepsis and anaphylaxis, as well as other vasoplegic conditions such as in cardiac surgery, increased levels of nitric oxide (NO) and activation of soluble guanylyl cyclase (sGC) are well documented and are responsible for the mismatch between macro- and microcirculation. NO has many functions, such as serving as a messenger molecule, regulating gene transcription and mRNA translation, as well as regulation of vascular tone [14]. NO diffuses freely from the endothelium into the neighboring VSMC and bloodstream causing vasodilation, inhibition of VSMC proliferation, platelet activation, and leukocyte adhesion [15]. Moreover, NO may cause blood vessel relaxation by activating the sGC, leading to activation of the cyclic guanosine monophosphate (cGMP)-dependent protein kinases (PKGs) [7].

In mammals, $\mathrm{NO}$ can be generated by three different isoforms of the enzyme NO synthase (NOS): neuronal NOS (nNOS, NOS1), inducible NOS (iNOS, NOS2), and endothelial NOS (eNOS, NOS3) [13]. All isoforms of NOS utilize Larginine as a substrate along with oxygen and reduced nicotinamide adenine dinucleotide phosphate as co-substrates. In addition, all isoforms of NOS bind calmodulin and calcium; activated calmodulin is important for the regulation of eNOS and nNOS activity. nNOS is found primarily in the brain and spinal cord where it modulates learning, neurogenesis, 
memory, and regulates blood pressure. Very recent evidence suggests a pivotal role of abnormal NO signaling and oxidative stress mediated by neuroinflammation in the pathogenesis of neurodegenerative diseases $[14,16]$. eNOS exists primarily in endothelial cells, but also occurs in other cell types including platelets and cardiac myocytes. The physiologic functions of eNOS include inhibition of platelet aggregation and adhesion and inhibition of leukocyte aggregation. The primary role of eNOS appears to be regulation of cardiovascular functions such as blood pressure. Bradykinin, thrombin, and histamine increase NO production and vasodilation by activating eNOS. In addition, inflammatory cytokines and PAMPs such as lipopolysaccharide (LPS) induce the synthesis of the third calcium-independent iNOS isoform. This results in an increase in NO of two to three orders of magnitude [14, 15]. iNOS was first identified in macrophages, but other cells such as hepatocytes, enterocytes, Paneth cells, or VSMC are sources of iNOS as well [15]. Excessive NO synthesis and induction of iNOS have been implicated in further promotion of vasodilation and hyporeactivity to pressor agents during sepsis [15]. The NO-mediated hypotension leads to severe hypoxia in peripheral vital organs, resulting in progressive organ failure. NO may also directly contribute to tissue and organ injury by its direct, peroxynitrite-mediated cytotoxic effects [15]. Interestingly during the late phase of shock there is an impairment of the biosynthesis of NO by eNOS in vascular endothelium, the constitutive form being downregulated as the inducible form is expressed [17].

Activation of sGC is an important signaling pathway of NO, resulting in the production of cGMP. sGC catalyze conversion of the purine nucleoside guanosine-5'-triphosphate to cGMP in response to various messengers such as peptide ligands, calcium influx, and NO. sGC activation in VSMC produces vasorelaxation and inhibits smooth muscle proliferation. In VSMC, the activation of the eNOS-sGC pathway is essential in order to increase permeability and proliferation [18].

Redundant activation of the NO-cGMP pathway has been associated with distributive shock such as sepsis and anaphylaxis [14, 19]. However, NO may exert protective effects through its capacity to counteract oxidative stress [16], extinguish apoptosis, prevent platelet and leukocyte adhesion, induce anti-inflammatory activity, and kill pathogens $[14,17]$. This dual personality of NO can help to explain why unselective NOS inhibitors fail to provide clinical benefits in patients with sepsis [14]. Therefore, nowadays clinical research is focusing on the so-called selective iNOS inhibitors and on NO scavengers, with the aim to further target the therapy on microcirculation impairment, prevent toxicity and/or shock caused by excessive NO, while preserving some essential $\mathrm{NO}$ activities in the proximity of its area of production.

\section{METHYLENE BLUE}

As a result of binding to the iron heme moiety of sGC and blocking sGC action in vascular smooth muscle, $\mathrm{MB}$ decreases the levels of cGMP and alleviates its vasorelaxant effect (Fig. 1) [20]. MB also has the ability to scavenge $\mathrm{NO}$ as well as to selectively inhibit iNOs [21]. When given intravenously, MB concentrations peak at $30 \mathrm{~min}$ with an onset of action of 30-60 min. It has a relatively large volume of distribution $(255 \pm 58 \mathrm{~L})$ and is highly protein bound (94\%). Excretion occurs via the bile, fecal, and renal routes [20-22]. Intravenous administration typically has a terminal plasma half-life of 5-6 h, and continuous infusions may be beneficial after the initial bolus for up to $48-72 \mathrm{~h}$. As a result of the short-term effects of $\mathrm{MB}$, a number of studies also evaluated prolonged infusions of $\mathrm{MB}$ with doses of $0.25-2 \mathrm{mg} / \mathrm{kg} / \mathrm{h}$, up to $120 \mathrm{~h}$ [20-22].

Perhaps, the most common use of $\mathrm{MB}$ is as a dye in clinical investigations of the gastrointestinal or urinary systems. MB has also been used in oncology for sentinel lymph node detection. A less common but well-established use of $\mathrm{MB}$ is the treatment of methemoglobinemia complicating topical benzocaine use, where $\mathrm{MB}$ hastens the conversion of methemoglobin to hemoglobin. $\mathrm{MB}$ has also been utilized in patients with congenital 


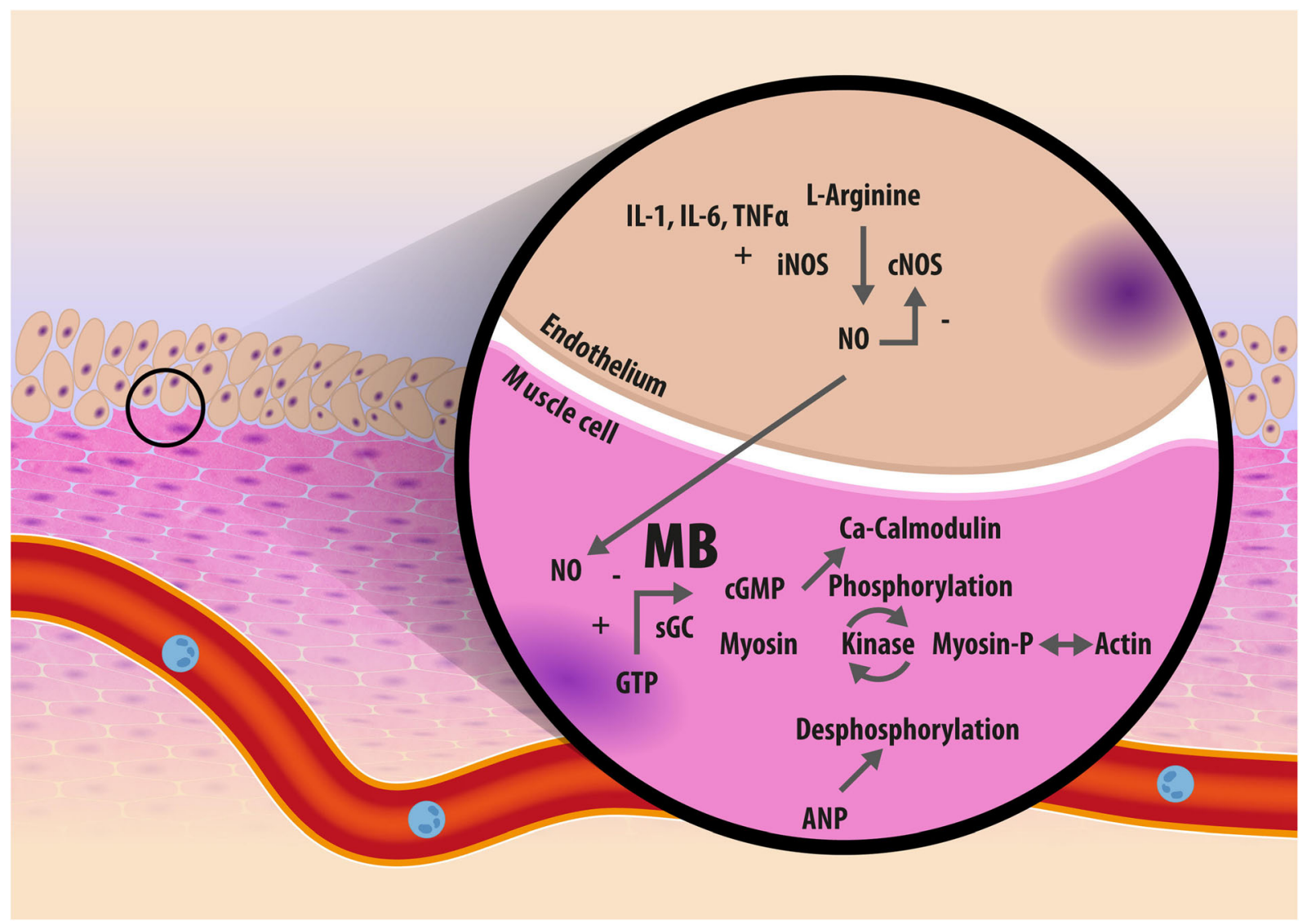

Fig. 1 Scheme of NO production and possible action of methylene blue. IL-1 interleukin-1, IL-6 interleukin-6, TNF $\alpha$ tumor necrosis factor alpha, NO nitric oxide, iNOS inducible nitric oxide synthase, cNOS constitutive nitric oxide synthase, MB methylene blue, sGC soluble guanylyl cyclase, cGMP cyclic guanosine monophosphate, GTP guanosine triphosphate, ANP atrial natriuretic peptide

\section{Methylene Blue and Septic Shock}

methemoglobinemia, priapism, neonatal $[20,21]$. In vasodilatory shock, a therapeutic bolus of $1-2 \mathrm{mg} / \mathrm{kg}$ is commonly administered over 10-20 min, or up to $1 \mathrm{~h}$. The appealing mechanism of action of $\mathrm{MB}$ (i.e., selectively blocking sGC as well as inhibiting iNOS) explains why it is regarded not as a pure vasoconstrictor but instead as a selective agent on the microcirculation dysregulation in cases of NO upregulation. Growing evidence is emerging regarding its use in several vasoplegic conditions such as sepsis, anaphylaxis, hemodialysis, cardiac surgery, and liver transplantation or end-stage liver disease [23-29].
Two randomized controlled trials evaluated the use of $\mathrm{MB}$ in treating hypotension secondary to septic shock $[27,28]$. In both studies, as well as in observational ones and case reports [29-35], MB was able to cause a statistically significant increase of MAP (see Table 2 for details of included studies). MB led to significant increases in systemic vascular resistance [29, 31, 32]. A recent meta-analysis shows that $\mathrm{MB}$ blue could significantly increase MAP in patients with refractory hypotension caused by vascular paralysis during the course of vasodilatory shock and decrease the lactate levels [36]. Administration of $\mathrm{MB}$ was able to facilitate the 


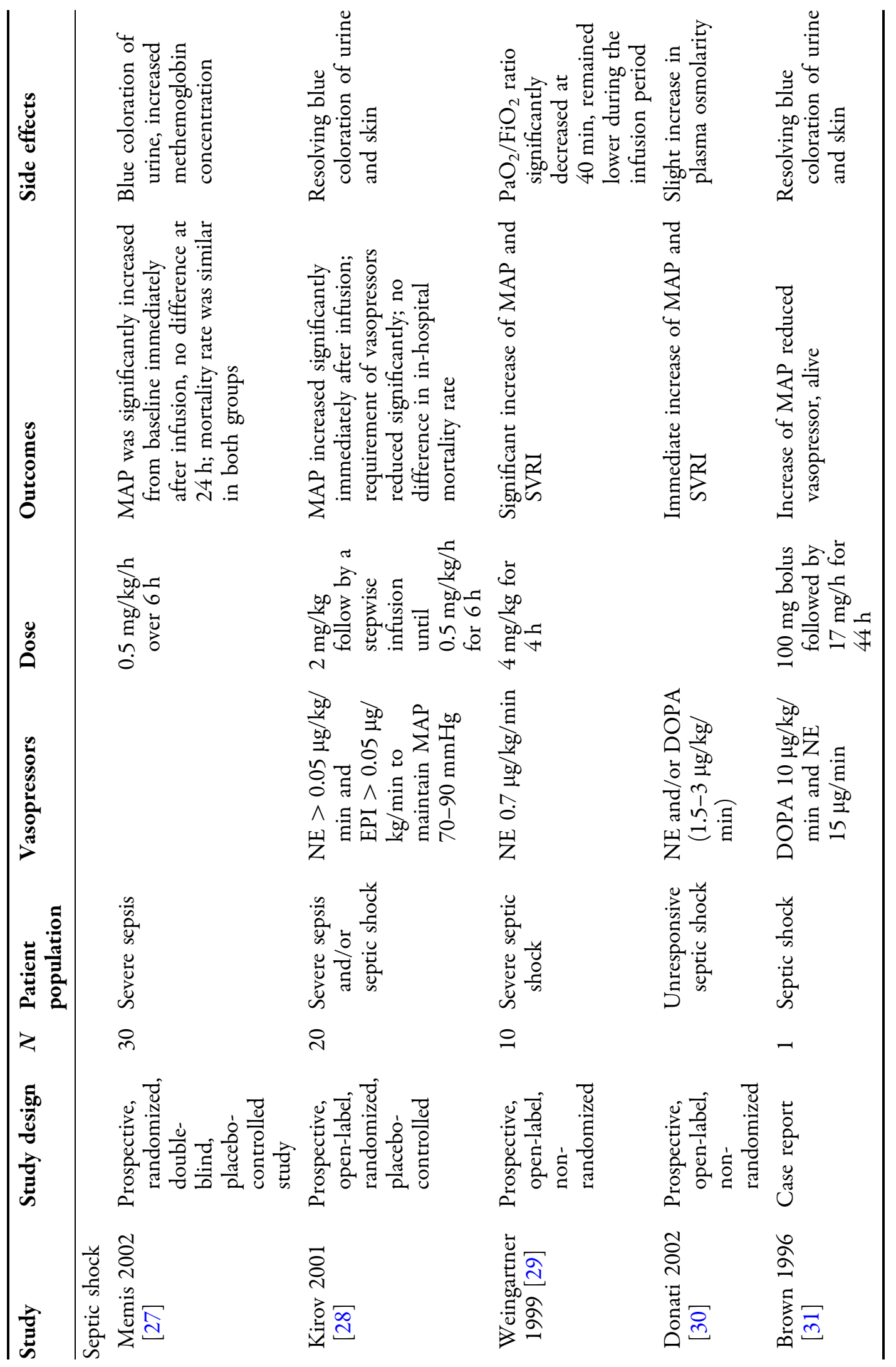




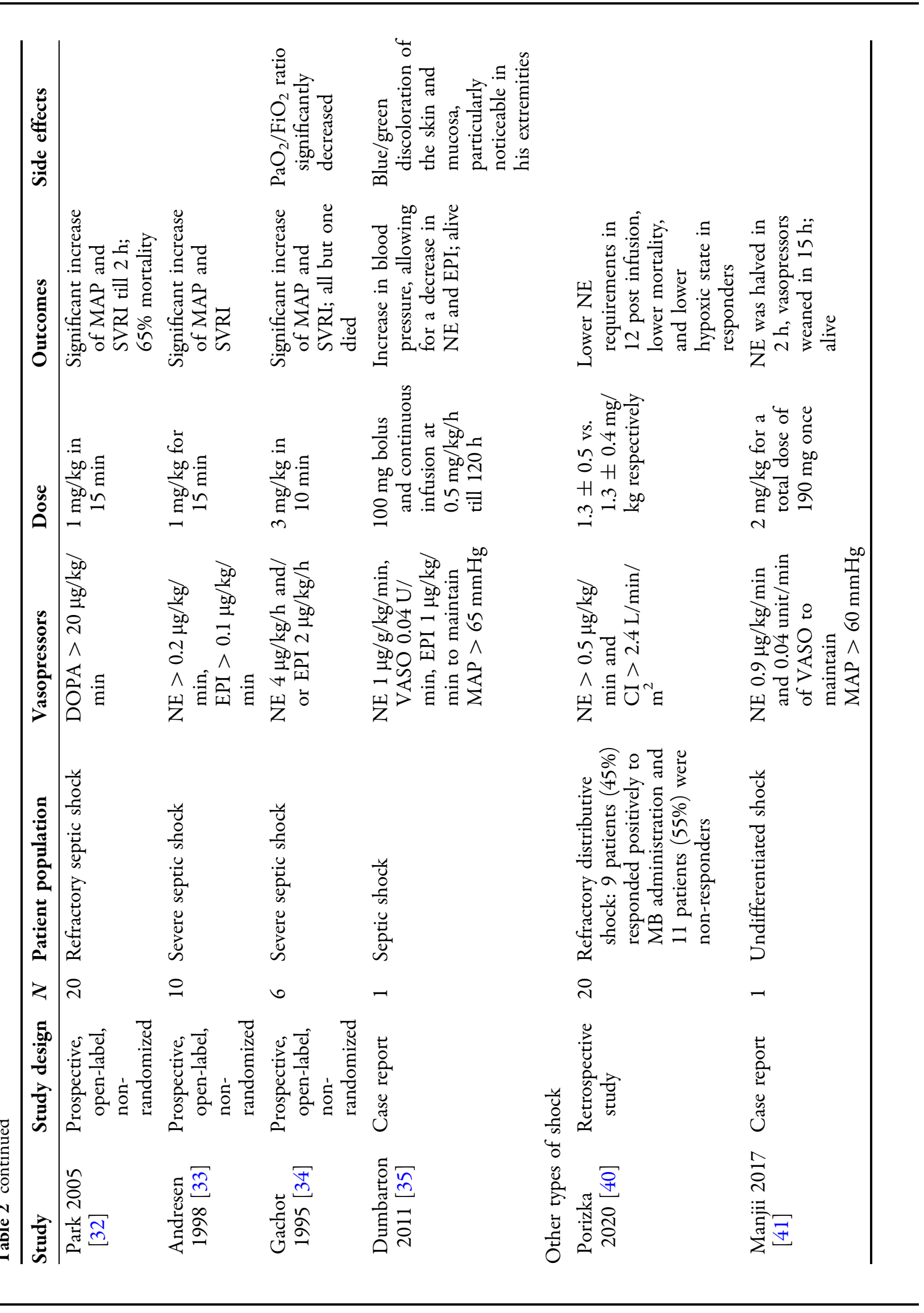




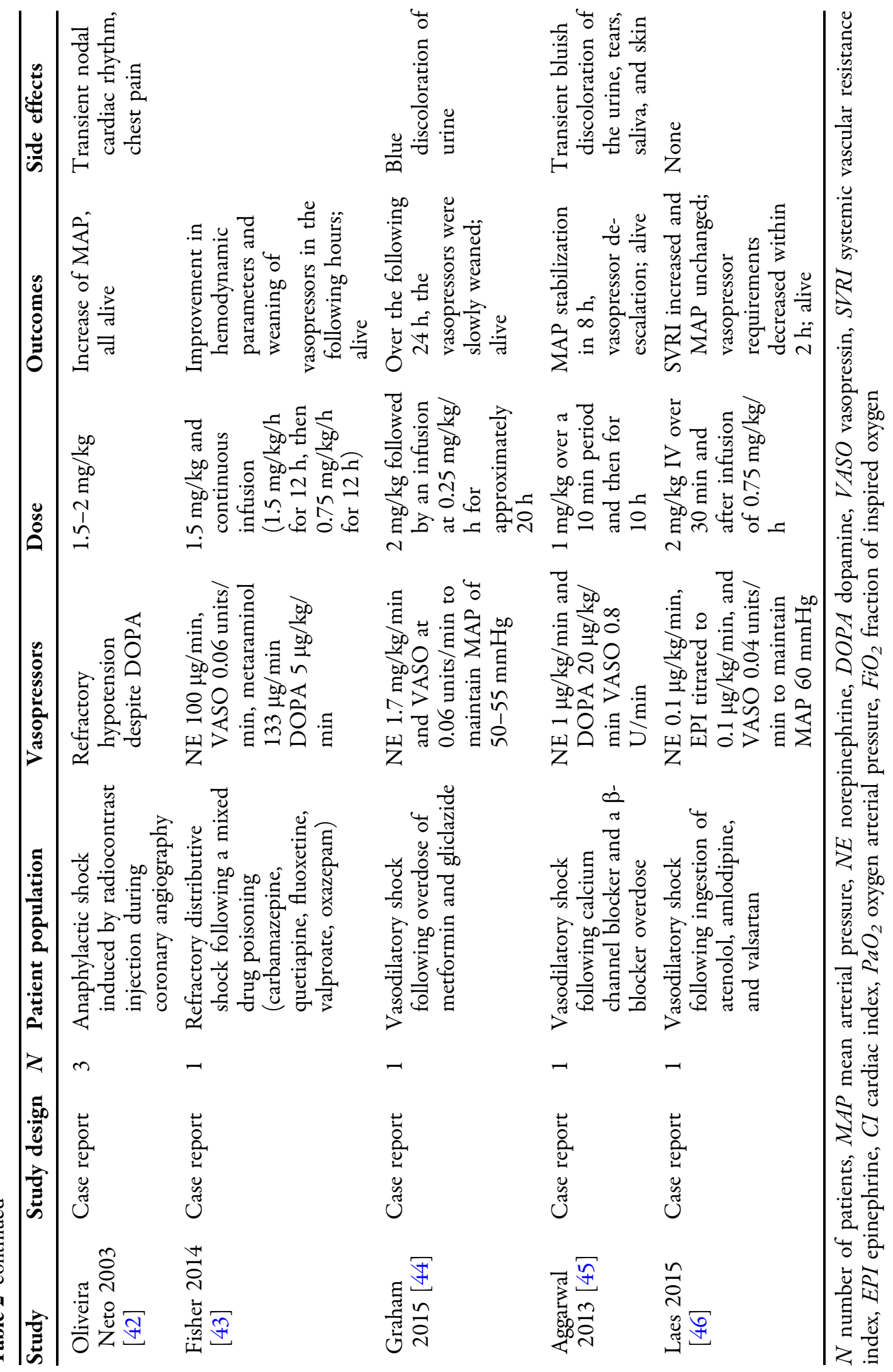


weaning of catecholamine vasopressors as well $[28,31,35]$.

However, the MB doses administered and concomitant vasopressor titration parameters were inconsistent among all studies. The reduction of catecholamines ranges from 2 up to $24 \mathrm{~h}$ after $\mathrm{MB}$ infusion. Moreover, several studies tested $\mathrm{MB}$ use in cases of refractory vasodilatory shock with no response to conventional treatment, and therefore started it late in treatment. This may not be the correct approach, since a possible "window of opportunity" for the MB's effectiveness in sepsis has been proposed [37]. In the first $8 \mathrm{~h}$, there is increased iNOS activity and sGC upregulation. In the second $8 \mathrm{~h}$, there is an absence of sGC expression and a downregulation of iNOS. In the third 8-h window, there is an upregulation of sGC and iNOS. Therefore, MB use as a last rescue therapeutic option goes against the aforementioned concepts, and it is possible that $\mathrm{MB}$ does not act (second window) or acts too late (third window) when the circulatory shock is metabolically irreversible, presenting high lactate levels and intractable metabolic acidosis. Perhaps it is more useful to consider MB not as a late rescue treatment but as an adjuvant drug to be used early (first window) [38].

Although MB may improve hemodynamics by increasing MAP, a corresponding mortality benefit was not seen overall. The meta-analysis by Belletti et al. [39], focusing on the effect of non-adrenergic vasopressors in patients with or at risk for vasodilatory shock (including MB), found that none of the drugs was associated with significant reduction in mortality when analyzed independently. A lack of overall mortality benefit may be attributed to the shortacting effects of MB. As a result of the shorter duration of action, prolonged or continuous infusions may be necessary in patients with persistent hypotension. A recent retrospective analysis of 20 critically ill patients with refractory shock gives new insight into the action of MB [40]. Patients were defined as responders with positive hemodynamic response to $\mathrm{MB}$ administration (10\% decrease of norepinephrine dose) and non-responders. There were $9(45 \%)$ responders and $11(55 \%)$ non-responders to administration of a single bolus of
MB. Those who responded had significantly improved survival compared to those with no hemodynamic response. Also, non-responders were in a more profound state of tissue hypoxia documented by significant metabolic acidosis and higher lactate levels compared to responders. The authors concluded that a patient's responsiveness to $\mathrm{MB}$ may depend on the degree of actual tissue hypoxia and anaerobic metabolism, thus confirming its beneficial effect early in the course of shock state before the profound ischemic tissue changes develop and vasoplegic syndrome progresses to its refractory phase. The mortality benefit seen in MB responders may likely be related to the lesser degree of tissue hypoxia rather than to the sole effect of $\mathrm{MB}$ and the decrease of vasopressor requirements.

\section{Methylene Blue and Other Types of Shock}

In addition to use in septic shock, MB has also been studied in anaphylactic and drug-induced shock or undifferentiated shock [41-46]. Medications involved include contrast medium, antidiabetics, antidepressants, and antihypertensives (e.g., amlodipine, atenolol, and valsar$\tan )$. For both indications, literature support was limited to case reports and case series. However, in the majority of cases, benefit was seen in terms of patient survival and reduction in catecholamine vasopressor. Again, clinical inference may be limited as a result of observational study designs, the unclear kind of shock (anaphylaxis, immune-mediated, or non-immune-mediated), the limit of publication bias (i.e., the tendency to publish only positive results), as well as the fact that results may be affected by potential confounders such as concomitant use of corticosteroids and the natural progression of shock.

\section{Safety}

MB was generally well tolerated in all studies: the main adverse effects reported were blue discoloration of the skin and more commonly of the urine. This effect is relatively harmless and reverses in a few days upon discontinuation 
of the medication. Other adverse effects known to occur with administration of $\mathrm{MB}$ include flushing, dizziness, nausea, and chest and limb pain.

Even though this topic is still discussed, in small studies on patients in septic shock, MB was found to lead to worsening arterial oxygenation and reduced ratios of arterial oxygen tension to fraction of inspired oxygen $(\mathrm{P} / \mathrm{F})$, because of inhibition of hypoxic pulmonary vasoconstriction and impaired alveolocapillary gas exchange in the lung $[29,34]$. To avoid these risks, it may be prudent to avoid use of higher doses in patients with acute lung injury and acute respiratory distress syndrome (ARDS), where the pulmonary elasticity is highly compromised [47]. MB may also lead to mesenteric vasoconstriction and compromised blood flow, in particular at high doses (up to $4 \mathrm{mg} / \mathrm{kg}$ ). Continuous peripheral infusion of MB for prolonged duration may lead to local cutaneous necrosis and administration (bolus and/or infusion) can also cause artificially low pulse oximetry readings because of the blue coloration. This is because its spectral absorption is similar to that of the difference between oxyhemoglobin and reduced hemoglobin.

Toxic manifestations of $\mathrm{MB}$ are dose related. At doses greater than $4 \mathrm{mg} / \mathrm{kg}$, MB may catalyze oxidation of the ferrous ion in hemoglobin and increase methemoglobin. Hemolysis, nausea and vomiting, chest pain, and hypertension have been reported for doses more than $7 \mathrm{mg} /$ $\mathrm{kg}$. At high doses $(>20 \mathrm{mg} / \mathrm{kg}), \mathrm{MB}$ can cause severe intravascular hemolysis, hyperbilirubinemia, and death.

Moreover, $\mathrm{MB}$ inhibits monoamine oxidase A, which is an enzyme responsible for breaking down serotonin in the brain. Serotonin syndrome has been reported in those taking antidepressant medications. Serotonin syndrome is a life-threatening condition that causes altered mental status, altered neuromuscular excitability, and autonomic instability.

In addition, $\mathrm{MB}$ inhibits cytochrome $\mathrm{P} 450$ (CYP) isozymes and may affect hepatic medication metabolism. Typically, medications with a narrow therapeutic index metabolized by the same cytochrome will be most affected. MB is metabolized by the liver and excreted by the kidneys. Patients with hepatic or renal dysfunction are at risk of toxicities and potential drug interactions.

The use of $\mathrm{MB}$ is contraindicated during pregnancy because of the increased expression of NO in the placenta and subsequent risk of fetal hypoxia following $\mathrm{MB}$ administration. Lastly, MB is contraindicated in patients with glucose-6-phosphate dehydrogenase deficiency and may cause hemolytic anemia owing to a decreased ability to reduce $\mathrm{MB}$ into its metabolites [10, 21, 48].

\section{CONCLUSIONS}

The role of $\mathrm{MB}$ as a catecholamine-sparing agent in the management of vasodilatory shock is under debate. The mechanism of action for NO inhibition in the management of vasodilatory shock appears promising, even though the limited data with inconsistent findings poses several doubts on its use in clinical practice. Owing to the benefits in terms of increasing MAP, increasing SVR, and reducing catecholamine vasopressor requirements, $\mathrm{MB}$ at a dose of $1-2 \mathrm{mg} / \mathrm{kg}$ IV bolus may be an option for use in patients with sepsis who remain hypotensive despite adequate fluid replacement and receiving multiple vasoactive agents $[21,22]$. Continuous infusions, up to $0.25-0.50 \mathrm{mg} / \mathrm{kg} / \mathrm{h}$, may be used in persistent hypotension owing to its short duration of action. It is also reasonable to avoid higher doses in patients with acute lung injury and ARDS because of the deleterious effects seen on pulmonary function. Recent evidence suggests that earlier use of MB (in the first $8 \mathrm{~h}$ of sepsis) could be more effective on NO action. Experience with the use of $\mathrm{MB}$ in anaphylactic shock is limited to case reports and it is unclear whether the reactions were anaphylaxis or anaphylactic shock, immune-mediated, or nonimmune-mediated.

Routine use of $\mathrm{MB}$ is not strongly recommended at the moment, but it may be appropriate as add-on therapy for its catecholaminesparing effects in certain vasoplegic scenarios. Further studies are needed to clarify which 
dosing strategies, which patients, and when MB could find a right place in therapy.

\section{Limitations of the Study}

This narrative review has explored and synthesized most of the published material regarding the clinical use of $\mathrm{MB}$ in the treatment of patients in shock. Better indications on its usefulness would derive from a systematic review with meta-analysis of the data. At the moment, this does not seem to be possible, considering the low number of randomized controlled trials of good quality studying the use of $\mathrm{MB}$ in standardized conditions. Hence, a narrative review has been preferred instead in order to stimulate the scientific discussion.

\section{ACKNOWLEDGEMENTS}

The authors wish to thank Mariella Fusco for her support in the selection of papers. They are also grateful to Luca Di Giacomo for the assistance with the graphic design.

Funding. This research has been possible thanks to an unconditional grant provided by the "Paolo Procacci Foundation-ONLUS", Via Tacito 7, 00193 Roma, Italy. It was also partially funded by a grant received by "Fondazione Internazionale Salvatore Maugeri", research project "Modello di Unità di Terapia del Dolore e di Cure Palliative, integrate con Associazioni di Volontariato". No Rapid Service Fee was received by the journal for the publication of this article.

Authorship. All named authors meet the International Committee of Medical Journal Editors (ICMJE) criteria for authorship for this article, take responsibility for the integrity of the work as a whole, and have given their approval for this version to be published.

Authorship Contributions. Filomena Puntillo drafted the initial manuscript. Alberto Pasqualucci has carefully searched the potential references. All the authors have contributed to review and ameliorate the quality of the paper and have reviewed and approved the final draft of the manuscript.

Disclosures. Filomena Puntillo, Mariateresa Giglio, Alberto Pasqualucci, and Nicola Brienza have nothing to disclose. Antonella Paladini and Giustino Varrassi are members of the journal's Editorial Board.

Compliance with Ethics Guidelines. This article is based on previously conducted studies and does not contain any studies with human participants or animals performed by any of the authors.

Open Access. This article is licensed under a Creative Commons Attribution-NonCommercial 4.0 International License, which permits any non-commercial use, sharing, adaptation, distribution and reproduction in any medium or format, as long as you give appropriate credit to the original author(s) and the source, provide a link to the Creative Commons licence, and indicate if changes were made. The images or other third party material in this article are included in the article's Creative Commons licence, unless indicated otherwise in a credit line to the material. If material is not included in the article's Creative Commons licence and your intended use is not permitted by statutory regulation or exceeds the permitted use, you will need to obtain permission directly from the copyright holder. To view a copy of this licence, visit http://creativecommons.org/licenses/by$\mathrm{nc} / 4.0 /$.

\section{REFERENCES}

1. Angus DC, van der Poll T. Severe sepsis and septic shock. N Engl J Med. 2013;369(9):840-51. https:// doi.org/10.1056/NEJMra1208623.

2. Scheeren TWL, Bakker J, DeBacker D, et al. Current use of vasopressors in septic shock. Ann Intensive Care. 2019;9(1):20. https://doi.org/10.1186/s13613019-0498-7.

3. Dünser MW, Hasibeder WR. Sympathetic overstimulation during critical illness: adverse effects of 
adrenergic stress. J Intensive Care Med. 2009;24(5): 293-316. https://doi.org/10.1177/ 0885066609340519.

4. Buckley MS, Barletta JF, Smithburger PL, Radosevich JJ, Kane-Gill SL. Catecholamine vasopressor support sparing strategies in vasodilatory shock. Pharmacotherapy. 2019;39(3):382-98. https://doi. org/10.1002/phar.2199.

5. Varrassi G, Marino B, Cosmi EV. Influence of methylprednisolone sodium succinate on the microcirculation. Acta Anaesth It. 1974;25:159-71.

6. De Backer D, Foulon P. Minimizing catecholamines and optimizing perfusion. Crit Care. 2019;23(Suppl 1):149. https://doi.org/10.1186/s13054-019-2433-6.

7. Lambden S, Creagh-Brown BC, Hunt J, Summers C, Forni LG. Definitions and pathophysiology of vasoplegic shock. Crit Care. 2018;22(1):174. https:// doi.org/10.1186/s13054-018-2102-1.

8. Vincent JL. Fluid management in the critically ill. Kidney Int. 2019;96(1):52-7. https://doi.org/10. 1016/j.kint.2018.11.047.

9. Hadian M, Pinsky M. Functional hemodynamic monitoring. Curr Opin Crit Care. 2007;13(3): 318-23. Ob013e32811e14dd.

10. Leone $\mathrm{M}$, Asfar $\mathrm{P}$, Radermacher $\mathrm{P}$, Vincent $\mathrm{JL}$, Martin C. Optimizing mean arterial pressure in septic shock: a critical reappraisal of the literature. Crit Care. 2015;19(1):101. https://doi.org/10.1186/ s13054-015-0794-z.

11. Cecconi M, De Backer D, Antonelli M, et al. Consensus on circulatory shock and hemodynamic monitoring. Task force of the European Society of Intensive Care Medicine. Intensive Care Med. 2014;40(12):1795-815. https://doi.org/10.1007/ s00134-014-3525-z.

12. Ince $\mathrm{C}$. Hemodynamic coherence and the rationale for monitoring the microcirculation. Crit Care. 2015;19(Suppl 3):S8. https://doi.org/10.1186/ cc14726.

13. Elbers $P$, Ince C. Mechanisms of critical illnessclassifying microcirculatory flow abnormalities in distributive shock. Crit Care. 2006;10(4):221. https://doi.org/10.1186/cc4969.

14. Forstermann U, Sessa W. Nitric oxide synthases: regulation and function. Eur Heart J. 2012;33(829-837):837a-. https://doi.org/10.1093/ eurheartj/ehr304.
15. Cauwels A. Nitric oxide in shock. Kidney Int. 2007;72:557-65. https://doi.org/10.1038/sj.ki. 5002340 .

16. Rekatsina M, Paladini A, Piroli A, Zis P, Pergolizzi J, Varrassi G. Pathophysiology and therapeutic perspectives of oxidative stress and neurodegenerative diseases: a narrative review. Adv Ther. 2020;37(1): 113-39. https://doi.org/10.1007/s12325-019. 01148-5.

17. Titheradge M. Nitric oxide in septic shock. Biochim Biophys Acta. 1999;1411(2-3):437-55. https://doi. org/10.1016/s0005-2728(99)00031-6.

18. Su Y. Regulation of endothelial nitric oxide synthase activity by protein-protein interaction. Curr Pharm Des. 2014;20(22):3514-20. https://doi.org/ $10.2174 / 13816128113196660752$.

19. Stawicki SP, Sims C, Sarani B, Grossman MD, Gracias VH. Methylene blue and vasoplegia: who, when, and how? Mini Rev Med Chem. 2008;8: 472-90. https://doi.org/10.2174/ 138955708784223477.

20. Jang DH, Nelson LS, Hoffman RS. Methylene blue for distributive shock: a potential new use of an old antidote. J Med Toxicol. 2013;9(3):242-9. https:// doi.org/10.1007/s13181-013-0298-7.

21. Tchen S, Sullivan JB. Clinical utility of midodrine and methylene blue as catecholamine-sparing agents in intensive care unit patients with shock. J Crit Care. 2020;57:148-56. https://doi.org/10. 1016/j.jcrc.2020.02.011.

22. Evora PRB. Broad spectrum vasopressors support sparing strategies in vasodilatory shock beyond the vascular receptors. Chest. 2020;157(2):471-2. https://doi.org/10.1016/j.chest.2019.08.2211.

23. Evora PRB, Alves Junior L, Ferreira CA, et al. Twenty years of vasoplegic syndrome treatment in heart surgery. Methylene blue revised. Rev Bras Cir Cardiovasc. 2015;30(1):84-92. https://doi.org/10.5935/ 1678-9741.20140115.

24. Kavanaugh M, Berumen J, Chu F, Yin J, Beitler J. Methylene blue utilization for refractory septic shock in the setting of cirrhosis as a bridge to successful liver-kidney transplant: case report and review of the literature. Chest. 2015;148(4, Suppl): 206A. https://doi.org/10.1378/chest.2267413.

25. Vilalva KH, Mumic FT, Silveira MRG, Mente ED, Evora PRB, Castro e Silva O. Use of methylene blue to treat hypovolemic shock followed by ischemiareperfusion injury in the postoperative orthotopic liver transplant patient: a case report. Exp Clin Transplant. 2018;16(4):511-4. https://doi.org/10. 6002/ect.2016.0041. 
26. Peer G, Itzhakov E, Wollman Y, et al. Methylene blue, a nitric oxide inhibitor, prevents haemodialysis hypotension. Nephrol Dial Transplant. 2001;16(7):1436-41. https://doi.org/10.1093/ndt/ 16.7.1436.

27. Memis D, Karamanlioglu B, Yuksel M, Gemlik I, Pamukcu Z. The influence of methylene blue infusion on cytokine levels during severe sepsis. Anaesth Intensive Care. 2002;30(6):755-62. https:// doi.org/10.1177/0310057X0203000606.

28. Kirov MY, Evgenov OV, Evgenov NV, et al. Infusion of methylene blue in human septic shock: a pilot, randomized, controlled study. Crit Care Med. 2001;29(10):1860-7. https://doi.org/10.1097/ 00003246-200110000-00002.

29. Weingartner R, Oliveira E, Oliveira ES, et al. Blockade of the action of nitric oxide in human septic shock increases systemic vascular resistance and has detrimental effects on pulmonary function after a short infusion of methylene blue. Braz J Med Biol Res. 1999;32(12):1505-13. https://doi.org/10.1590/ s0100-879x1999001200009.

30. Donati A, Conti G, Loggi S, et al. Does methylene blue administration to septic shock patients affect vascular permeability and blood volume? Crit Care Med. 2002;30(10):2271-7. https://doi.org/10.1097/ 00003246-200210000-00015.

31. Brown G, Frankl D, Phang T. Continuous infusion of methylene blue for septic shock. Postgrad Med J. 1996;72(852):612-4. https://doi.org/10.1136/pgmj. 72.852.612.

32. Park B-K, Shim T-S, Lim C-M, et al. The effects of methylene blue on hemodynamic parameters and cytokine levels in refractory septic shock. Korean J Intern Med. 2005;20(2):123-8. https://doi.org/10. 3904/kjim.2005.20.2.123.

33. Andresen M, Dougnac A, Diaz O, et al. Use of methylene blue in patients with refractory septic shock: impact on hemodynamics and gas exchange. J Crit Care. 1998;13(4):164-8. https:// doi.org/10.1016/s0883-9441(98)90001-6.

34. Gachot B, Bedos JP, Veber B, Wolff M, Regnier B. Short-term effects of methylene blue on hemodynamics and gas exchange in humans with septic shock. Intensive Care Med. 1995;21(12):1027-31. https://doi.org/10.1007/BF01700666.

35. Dumbarton TC, Minor S, Yeung CK, Green R. Prolonged methylene blue infusion in refractory septic shock: a case report. Can J Anesth. 2011;58(4): 401-5. https://doi.org/10.1007/s12630-011-9458-x.

36. Zhang X, Gao Y, Pan P, Wang Y, Li W, Yu X. Methylene blue in the treatment of vasodilatory shock: a meta-analysis. Zhonghua Wei Zhong Bing Ji Jiu Yi Xue. 2017;29(11):982-7. https://doi.org/10. 3760/cma.j.issn.2095-4352.2017.11.005.

37. Evora PRB, de Freitas Ribeiro PJ, de Andrade Vicente $\mathrm{WV}$, et al. Methylene blue for vasoplegic syndrome treatment in heart surgery: fifteen years of questions, answers, doubts and certainties. Rev Bras Cir Cardiovasc. 2009;24(3):279-88. https://doi.org/10. 1590/s0102-76382009000400005.

38. Evora PRB. Methylene blue does not have to be considered only as rescue therapy for distributive shock. J Med Toxicol. 2013;9(4):426. https://doi. org/10.1007/s13181-013-0333-8.

39. Belletti A, Musu M, Silvetti S, et al. Non-adrenergic vasopressors in patients with or at risk for vasodilatory shock. A systematic review and metaanalysis of randomized trials. PLoS One. 2015;10(11):e0142605. https://doi.org/10.1371/ journal.pone.0142605.

40. Porizka M, Kopecky P, Dvorakova H, et al. Methylene blue administration in patients with refractory distributive shock-a retrospective study. Sci Rep. 2020;10(1):1828. https://doi.org/10.1038/s41598020-58828-4.

41. Manji F, Benjamin Wierstra B, Posadas J. Severe undifferentiated vasoplegic shock refractory to vasoactive agents treated with methylene blue. Case Rep Crit Care. 2017;2017:8747326. https:// doi.org/10.1155/2017/8747326.

42. Oliveira Neto AM, Duarte NM, Vicente WVA, Viaro F, Evora PRB. Methylene blue: an effective treatment for contrast medium-induced anaphylaxis. Med Sci Monit. 2003;9(11):CS102-CS106.

43. Fisher J, Taori G, Braitberg G, Graudins A. Methylene blue used in the treatment of refractory shock resulting from drug poisoning. Clin Toxicol. 2014;52:63-5. https://doi.org/10.3109/15563650. 2013.870343 .

44. Graham RE, Cartner M, Winearls J. A severe case of vasoplegic shock following metformin overdose successfully treated with methylene blue as a last line therapy. BMJ Case Rep. 2015;2014: bcr201521022. https://doi.org/10.1136/bcr-2015210229.

45. Aggarwal N, Kupfer Y, Seneviratne C, Tessler S. Methylene blue reverses recalcitrant shock in $\beta$ blocker and calcium channel blocker overdose. BMJ Case Rep. 2013;2013:bcr2012007402. https://doi. org/10.1136/bcr-2012-007402.

46. Laes JR, Williams DM, Cole JB. Improvement in hemodynamics after methylene blue administration in drug-induced vasodilatory shock: a case 
report. J Med Toxicol. 2015;11(4):460-3. https:// doi.org/10.1007/s13181-015-0500-1.

47. Ranieri VM, Brienza N, Santostasi S, et al. Impairment of lung and chest wall mechanics in patients with acute respiratory distress syndrome: role of abdominal distension. Am J Respir Crit Care Med. 1997;156(4 Pt 1):1082-91.

48. McCartney SL, Duce L, Ghadimi K. Intraoperative vasoplegia: methylene blue to the rescue! Curr Opin Anesthesiol. 2017;31(1):43-9. https://doi.org/10. 1097/ACO.0000000000000548. 